\title{
LA GRADUACIÓN: UN RETO PARA LOS ESTUDIANTES UNIVERSITARIOS DE PRIMERA GENERACIÓN
}

\author{
Ana Fanelli \\ Investigadora principal del Consejo Nacional de \\ Investigaciones Científicas y Técnicas (CONICET) de \\ Argentina, en el Centro de Estudios de Estado y Sociedad \\ (CEDES). \\ anafan@cedes.org
}

$\mathrm{L}$ as universidades públicas de la Argentina se caracterizan por presentar pocas restricciones formales y económicas en la transición entre la escuela media y la universidad. Por un lado, los mecanismos de admisión a las carreras de grado en las universidades nacionales no son selectivos, ya que no se establece un número máximo de aspirantes a ingresar por carrera, ni se implementan pruebas de aptitud o conocimiento al final de la escuela media para el acceso a los estudios universitarios. La modalidad más frecuente era, hasta el año 2015, el acceso a través de cursos o exámenes preuniversitarios que los aspirantes debían aprobar como condición para ingresar a las carreras y universidades seleccionadas y convertirse, entonces, en estudiantes de estas. Finalmente, en unos pocos casos, especialmente en algunas carreras de grado como medicina, el ingreso solía ser mediante examen y cupo implícito.

\section{c. Los mecanismos de admisión a las carreras de grado en las universidades nacionales no son selectivos}

Por otro lado, por los estudios presenciales de grado, las universidades nacionales no cobran aranceles, con la excepción de aquellas carreras de grado que se dictan bajo la modalidad a distancia o virtual y los llamados cursos de "postítulo", destinados a que los egresados de los profesorados obtengan el grado de licenciatura.

\section{Nueva legislación que promueve el acceso con menos restricciones y más gratuidad}

Una nueva ley, sancionada en octubre de 2015 e impulsada por una diputada perteneciente al entonces partido político a cargo del gobierno nacional, el Frente para la Victoria, buscó avanzar aún más en el acceso libre y la gratuidad, prohibiendo todo tipo de examen o curso de admisión e incluyendo, ahora también, los cursos a distancia y los postítulos dentro de la exigencia de gratuidad.

Todavía no se conoce cuál será el efecto final de esta ley, ya que la justicia declaró inconstitucional uno de los artículos que establece el ingreso libre e irrestricto por considerar que este pasa por encima de la autonomía universitaria. Este fallo fue en respuesta a un recurso de amparo presentado por la Universidad Nacional de la Matanza. Por el momento, la estrategia desplegada por algunas universidades nacionales para adecuarse a la ley, sin renunciar a la posibilidad de aplicar ciertos mecanismos de admisión, fue incorporar estos cursos de nivelación o preuniversitarios como parte de las materias del primer año de las carreras. En suma, los aspirantes se convierten en alumnos no bien se inscriben a la universidad, pero sólo podrán continuar estudiando 
si logran aprobar las materias de estos cursos de primer año. Esta es la modalidad que también aplica la Universidad de Buenos Aires a través del Ciclo básico común que los estudiantes deben aprobar como requisito previo a la continuación de sus estudios en la carrera elegida.

Lo cierto es que la ausencia de estas barreras académicas al ingreso y económicas, vía gratuidad de los estudios de grado, no garantizan por completo la equidad de los jóvenes en lo que respecta a la permanencia y graduación en los estudios universitarios de grado. Por el contrario, estas políticas han reforzado las prácticas de selección que, de modo descentralizado, realizan personalmente los docentes al frente de las cátedras, en especial, a lo largo del primer año.

\section{Inequidad en la retención y en la graduación}

En una investigación realizada en conjunto con Cecilia Adrogué, investigadora del CONICET, pudimos constatar la inequidad que presenta nuestro sector universitario en relación con la retención y graduación de sus estudiantes. Utilizando como fuente la Encuesta permanente de hogares para los años 2003-2015, en primer lugar, hemos calculado las tasas globales de abandono y graduación por nivel socioeconómico de los jóvenes comprendidos en el grupo etario de 18 a 30 años, quienes asistieron a la universidad pero ya no lo hacían más. Al respecto se observa que, mientras la tasa global de graduación es notoriamente mayor para los que habitan hogares con ingreso per cápita más alto, la tasa global de abandono es de $68 \%$ y $65 \%$ entre los estudiantes que residen en los hogares del primer y segundo quintil de ingresos per cápita más bajos respectivamente, frente a una tasa del $23 \%$ en los estudiantes de los hogares de mayor ingreso per cápita.

En segundo lugar, estudiamos cuáles son los principales factores asociados a este abandono. Por un lado, esta investigación revela lo esperable, es decir, que cuanto menor es el ingreso per cápita del hogar, mayor es la probabilidad de abandonar. Los estudiantes del estrato de menor ingreso abandonan 2,7 veces por cada vez que lo hacen los estudiantes del estrato más alto. Empero, el resultado más interesante de nuestra investigación es que, controlando por género, nivel socioeconómico de hogar, actividad laboral y edad, los estudiantes universitarios de primera generación, es decir, aquellos cuyos padres no son graduados universitarios, tienen aproximadamente 2,65 veces más probabilidad de abandonar que aquellos cuya madre o padre son graduados universitarios. Este hallazgo pone en evidencia la importancia de otras variables que se expresan indirectamente en la condición de ser el(la) primer(a) estudiante en la familia. Estos resultados son, además, consistentes con los estudios realizados en los Estados Unidos por Susan Choy y destacan la importancia del capital cultural y social que poseen los padres con educación superior, influyendo en las distintas etapas del acceso, persistencia y posterior graduación de sus hijos.

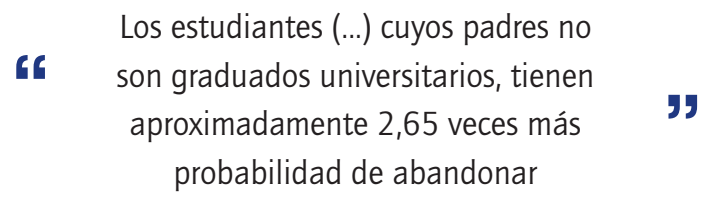

En el contexto de un sector universitario con acceso abierto, sin exámenes de ingreso selectivos en la mayoría de las universidades y carreras, es de esperar que, de no mediar políticas que compensen las desigualdades en términos de capital cultural, los estudiantes fracasen a lo largo del primer año. Esto es también lo que encontramos en nuestro estudio, ya que quienes están en el primer año tienen una probabilidad 1,7 veces mayor de abandonar que aquellos que ya aprobaron algún año de estudio.

Estos resultados ponen en primer plano la necesidad de orientar las políticas públicas e institucionales hacia el diseño y puesta en marcha de nuevas estrategias organizacionales, con el fin de mejorar los índices de retención y graduación universitarios. Las acciones emprendidas en el pasado que se reafirman con la nueva ley, acceso libre y gratuidad, claramente no bastan para alcanzar los objetivos de inclusión social y mejora del capital humano del país. 